\title{
Analysis on the Influencing Factors and Causes of China's High Housing Prices
}

\author{
Zekai Zhang ${ }^{1, *}$ \\ ${ }^{1}$ The Williams High School \\ *Corresponding author. Email: zzhang@williamsschool.org

\begin{abstract}
High housing prices are currently a major problem facing Chinese cities, and the related factors are comprehensive and diverse. Based on the actual situation, it is not difficult to find that only when the government takes the lead, combines the economic power of the real estate market with the principles of socialism, takes into account the interests of all parties, breaks down each, and establishes a legalized real estate planning implementation system, can the real estate industry truly become an important force to promote the sustainable development of China's economy.
\end{abstract}

Keywords: Influencing Factors, Causes Analysis, High Housing Prices

\section{INTRODUCTION}

Currently, housing prices are high and prices are rising year by year. High housing prices have become one of the phenomena of concern to the entire society. Ordinary families can't afford a house, and exhausting all the house purchases brings tremendous pressure, which has triggered dissatisfaction with high housing prices. The government has also adopted various control measures to stabilize housing prices, but they have not played a role in restraining housing price growth. The current sustained high housing prices have seriously harmed the healthy development of the national economy. The emergence of real estate bubbles will cause the economy to stagnate, and high housing prices will cause a series of social and economic problems. Economic sociology studies the issue of high housing prices from multiple perspectives, while paying attention to the economy and society, and promoting the coordinated development between the two.

\section{LITERATURE REVIEW}

There have been many theoretical studies around the housing price issue. Zhou Tianyong believes that the intensification of China's urbanization process and the current land management system have promoted the rapid rise of China's housing prices. Li Xiangqun also analyzed the causal relationship between land price increase and housing price increase from the perspective of land supply management, and believed that the land management system should be continuously improved to control housing price increase. Su Guoshuai, Cao Mingxing, and Shi Jian analyzed the high housing prices from the perspective of the fiscal system [1]. They believe that under the existing fiscal and taxation system, local governments rely on land for taxation, which drives up housing prices. Chen Bo analyzed the reasons for the high housing prices from various aspects such as the land transfer system, the real estate market system, the illegal operations of developers and speculators [2]. Zhang Zhenhua believes that high housing prices are affected by both economic factors and political factors, and he believes that more attention should be paid to the role of political factors in promoting housing prices [3]. Domestic scholars' research on the causes of high housing prices can be summarized into five categories: one is "supply and demand theory"; the other is "cost theory", high land prices lead to high costs, and rising costs lead to higher housing prices; the third is "system theory" The defects in the existing land management system and fiscal and taxation system have promoted the increase in housing prices. The fourth is "monetary factor theory; the fifth is "the theory of power imbalance among interest groups".

\section{CHINA'S REAL ESTATE MARKET}

\subsection{China's commercial housing land system}

"Land finance" refers to the fact that some local governments rely on the income from the transfer of 
land use rights to maintain local fiscal expenditures. They are extra-budgetary revenues, also known as the second fiscal (first fiscal refers to taxes). Since the "two taxation system" reform in 1994, the local government's income from land finance has increasingly become the main source of local government's fiscal revenue. During the more than 20 years since the advent of China's land finance, local governments have invested a large amount of land fiscal revenue in urban infrastructure construction [4]. Public welfare undertakings such as education, health care and transportation in China have developed rapidly in a short period of time. As of 2018, China's urbanization rate has reached $59.58 \%$, and the urbanization rate of the registered population has reached $43.47 \%$. China's urbanization process has been achieved in decades [5]. With the brilliant achievements, the contribution of land finance should be worthy of recognition. Based on the unique system of public ownership of urban land in China, the financial attributes of urban land are set as a kind of credit endorsement in China. With the huge financing capacity of land, local governments can implement Competent tax deductions and land subsidies. Although Chinese companies bear a great "tax burden", the local government subsidizes Chinese companies through the income from land finance, so that the "tax burden" of Chinese companies can be bridged. This way of supporting enterprises by local governments has enabled Chinese enterprises to develop rapidly in decades, and China has become a new "world factory" [6].

Everything has two sides, and land finance is also a "double-edged sword." While land finance plays a huge role, it also creates many problems.

Land finance has led to the excessive expansion of Chinese cities and will face a situation of no land available in the future. This development method is not sustainable. When local governments obtain land transfer funds through land financial transfers, the scale of cities has also expanded. After more than 20 years of development, Chinese cities have greatly expanded in scale. According to the relevant data of the "China Urban Statistical Yearbook": China's urban built-up area is expanding rapidly. It is true that this has strengthened China's urban development and increased the urbanization rate, but this expansion is based on the annexation of rural collective land. Accompanied by this expansion are the sharp decline in the area of cultivated land, the loss of land by farmers, the low compensation standard for land acquisition, and even some illegal land issues. In addition, there is less and less rural land around cities [7]. In the future, cities may face a situation of no land to requisition and land available. This way of overdrawing future development space will not be sustainable [8].
Bring serious waste of resources and funds. Once local governments paid special attention to GDP indicators. Each stage of the real estate construction cycle will contribute a huge GDP output, causing local governments to be keen on land transfers. After the local government collected the land transfer fee, the real estate developer obtained the land transfer right, and high GDP output began with the development and construction of real estate [9]. From the demolition, construction, and delivery of real estate by real estate agents, to the decoration and move-in of home buyers, and the construction of related infrastructure, each stage consumes a lot of resources and funds. With the continuous progress of real estate development and construction, the supply of the real estate industry has gradually exceeded demand. Many built houses are unoccupied, and a large number of building materials such as steel boats and cement have been consumed. The funds for purchasing these building materials have supported local resources. GDP. Such a cycle has caused a serious waste of resources and funds [10].

As a result, housing prices are too high, and most people cannot afford it, widening the gap between the rich and the poor between those with and without houses; the real estate industry has a serious bubble and there are financial risks. In order to obtain more land transfer fees, the local government transfers the land through bidding, listing, auction and other methods [11]. Only the highest bidder can compete for the use of the land. This makes the cost of land acquisition for real estate developers stay high and push up. In addition to housing prices, China's housing prices have long been beyond the reach of many people. The gap between the rich and the poor between those with and without houses has rapidly widened in just over 20 years, which has increased social instability to a certain extent; It is high, but China has a large population base and a large number of real estate buyers. Most of the buyers who just need real estate pay a down payment first [12]. The rest of the housing payment is obtained through bank loans. The total amount of housing loans continues to increase. Long-term accumulation has made the real estate bubble worse. According to data from the Central Bank: As of September 2018, China's total personal mortgage loans reached 2,497 trillion yuan, which puts China's banking industry facing systemic financial risks [13].

\subsection{China's commercial housing credit system}

Starting from October 8, 2019, the interest rate of newly issued commercial personal housing loans will be formed based on the price quoted rate of the corresponding period of the loan in the most recent month. This reform measure, known as the "New Mortgage Deal", has aroused many concerns. Most 
interpretations start from the interest rate formation mechanism and analyze the different impacts of policies on different housing groups. It is generally believed that the interest burden before and after the reform is equivalent, and the short-term effect on the real estate market is not obvious. It is more suitable for precise control and city-specific policies.

Third, from the perspective of macroeconomic control, real estate will never become a short-term means of stimulating growth. In order to avoid the big ups and downs of house prices, especially in hotspots, mortgage interest rates, as an important part of house purchase costs, will inevitably be subject to timely and appropriate pre-adjustment and fine-tuning, and will inevitably obey and serve the goals and overall situation of regulation. On the other hand, the recent construction of various indemnificatory and policy-oriented housing, such as Shanghai's inclusion of migrants in the scope of declarations of shared property housing, mostly falls into the category of "first set, first loan", and loan approval enjoys a certain degree of preferential treatment, but in fact it is divided A considerable part of credit demand has supported the overall stability of mortgage interest rates.

In the final analysis, the development of the real estate market must implement the "people-centered" development philosophy; the regulation of the real estate market will ultimately focus on the main line of common prosperity. Since the reform and opening up, the per capita housing area in urban areas has jumped from 6.7 square meters to 36.6 square meters, which is a remarkable achievement. Looking forward to the real estate market in the second half of urbanization, we have a dynamic micro foundation, a solid and reliable meso guarantee, and multiple and efficient macro tools. As long as we rely on scientific planning, reasonable guidance, and prudent supervision, we can achieve the goal of living there.

\section{DETERMINANTS OF CHINA'S HIGH HOUSING PRICES}

a) Loose monetary policy enables sufficient supply of loanable funds. China's current loose monetary policy has allowed real estate developers to have sufficient funds so that they can maintain their capital turnover smoothly without lowering housing prices.

b) Imbalance between supply and demand in the real estate market. The relationship between supply and demand in the real estate market is the determinant of its equilibrium price. Developers have increased the supply of commercial housing when developing their positioning, which has caused the supply of affordable housing to shrink greatly and the supply structure has been severely distorted. At the same time, developers further undermine the structure of the real estate market. In order to maximize profits, developers have exploited the loopholes in the current domestic regulations on commercial housing development that are not very strict. They have increased the proportion of high-end large-scale residential houses, resulting in the marginal greening of affordable housing and low-rent housing, and the number of small-scale commercial housing there are also very few, resulting in a serious demand for rigid housing in short supply. In short, because the market has less development of ordinary low- and medium-priced housing, effective supply is extremely scarce, and the equilibrium price cannot be reduced, resulting in the high level of housing prices.

c) Local land finance and taxation finance are unreasonable. China's local government is not only the policy maker of the real estate market, but also the supplier of the land market, becoming the main body of interest in the real estate market. Since the implementation of the tax-sharing system in the country, the lack of money in local finance has worsened, and most cities lack profitable industries. Land sales have become an important source of income for them, making them too dependent on "land sales, and it is difficult to cooperate with the central government in regulating housing prices. The situation where the rise is out of control.

d) Residents have strong expectations of rising housing prices. Faced with such a severe dilemma of high housing prices, people are doing everything possible to raise funds to buy houses. The reason is simple, "If you don't buy now, you will be more expensive in the future. The reason is first. In order to reduce the loss caused by inflation, ordinary residents regard buying a house as an investment that is simple and easy to operate, without losing money. Second, real estate developers use public opinion to trumpet that "housing prices will only rise but not fall", leading to strong expectations of consumers for housing price rises, scrambling to buy houses in advance, further contributing to the momentum of housing price rises.

\section{CONCLUSION}

Based on the above analysis of the causes of high housing prices, the author believes that the following aspects should be addressed:

\subsection{Establish and improve laws and regulations related to real estate}

Formulate and implement a series of laws and regulations on guaranteeing residential housing, ensuring a reasonable supply of affordable housing and low-rent housing, so that the government has a law to 
follow in solving the housing problem, and will solve the people's livelihood problem.

Formulate and implement relevant laws and policies for legal land transactions, clearly stipulate the qualifications of both parties to land transactions, and ensure the fairness of the transaction process and the benefit of the results of the transaction. The central government should take back the rights of local governments to control land transactions, make overall management, and distribute profits from transactions to local governments in proportion to the standardization of land transactions.

The legislation clearly stipulates the transaction qualifications of both buyers and sellers of houses. Sellers are not allowed to sell real estate at will within a certain period of time. Real-name system for house purchases is implemented to limit the number of houses purchased. Malicious real estate speculation and house price bidding are cracked down according to law.

The legislation clarifies the conditions that real estate companies should have for loans and stipulates that their existing assets should be guaranteed. When a lender makes a house purchase loan, the bank shall strictly follow the regulations that the house purchased must meet the actual needs of the lender to implement the loan. $\theta$. Clearly stipulate the highest price of local housing and the rent level of houses of different quality and specifications in various cities

\subsection{Establish a multi-level housing security system}

Establish and improve relevant legal systems for the application, investment, construction and management of affordable housing and low-rent housing, and regulate their implementation procedures from both quantitative and qualitative aspects.

We will implement policies to support multi-channel financing of affordable housing and build a practical and diversified financing model. At the same time, corruption should be severely punished to ensure sufficient funds for the construction of affordable housing and are truly used to solve the shortage of affordable housing.

The central government clearly stipulates the proportion of land used for housing protection by local governments, and local governments follow the regulations and set reasonable land price ceilings based on the actual conditions of each region. At the same time, we will strengthen the dynamic supervision of real estate land supply and development and utilization, vigorously promote the rectification and cleanup of idle land, and severely investigate and deal with real estate violations. In addition, it is necessary to clearly define the specific location of the land for security housing, and it is strictly forbidden to place all security housing in areas with remote locations, inconvenient transportation and extremely imperfect infrastructure.

Urban planners should professionally and scientifically carry out spatial planning, architectural design and residential function innovation, improve the construction level of security housing, achieve high land efficiency and high quality, and meet the residential needs of residents.

Clearly formulate a security housing supervision mechanism, set up a "national-local level" security housing regulatory agency, and strictly deal with violations in strict accordance with laws and regulations. In addition, the supervisory agency should be composed of multiple departments related to social housing, and regularly hold social housing construction coordination meetings to ensure that the construction process of social housing is scientific and reasonable.

\subsection{Establish a housing consumption model in line with national conditions}

Establish a resource-intensive housing consumption model, focusing on low- and medium-priced, small and medium-sized apartments, and meeting the actual housing needs of low- and middle-income families as the national standard.

Guide citizens to establish the concept of housing gradient consumption, promote the rental of housing, and disperse the pressure of housing tension.

Improve the real estate finance, taxation and credit policies. A large amount of business tax is levied on malicious real estate speculators; the deed tax on housing transactions shall be reformed, and the deed tax rate shall be determined according to the size of the area; tax and credit incentives shall be given to those who purchase small and medium-sized apartment houses.

\subsection{Strengthen the government's macro- control of the real estate market}

The central government takes administrative measures to improve systemic laws and regulations related to real estate development. Local governments use this as a basis to formulate local control policies, establish and rationalize housing price formation mechanisms, standardize market order, open fair transactions in accordance with the law, and strictly punish malicious speculation and Corruption, etc.

The government and the media should vigorously popularize real estate-related knowledge and the risk of "real estate speculation" investment behavior, and 
timely adjust residents' expected attitudes toward housing prices to return their housing consumption concepts to the right path.

Relevant government departments that formulate laws and regulations should collect real estate-related information and conduct scientific analysis at all times, and use this as a basis to formulate and adjust feasible regulations and policies to achieve the purpose of effectively regulating housing prices.

\section{REFERENCES}

[1] Yang Fei. Analysis of supply and demand and countermeasures for the causes of high housing prices in China $[\mathrm{J}]$. Economics and Management, 2019 (1): 74-76.

[2] An Tifu. On Land Finance and Real Estate Market Regulation [J]. Local Finance Research, 2018 (2): 8-12.

[3] Shi Jiyuan. Housing slaves, housing prices and governance $[\mathrm{M}]$. Shanghai: Shanghai University of Finance and Economics Press, 2019.

[4] Analysis of the economic effect of China's real estate tax collection [J]. Shi Guifen, Chu Hanyu. Journal of Northeast Normal University (Philosophy and Social Sciences Edition). 2019(05)

[5] Evolution of Land Finance: Transition from Land Acquisition to Taxation? Based on the Analysis of Law and Economics [J]. Zhang Leilei. Exploration of Economic Issues. 2019(07)

[6] Land function alienation and the sustainability of China's economic growth [J]. Shen Kunrong, Zhao Qian. Economist. 2019(05)

[7] Research on the problems caused by local government land finance and solutions[J]. Yu Xinqiao. Northern Economy and Trade. 2019(04)

[8] Is it "Land Finance" or "Land Finance"? The growth logic of reform and the transition risk in the new era[J]. Zhao Yanjing. Cultural Aspects. 2019(02)

[9] A review of research on regional differences in land finance $[\mathrm{J}]$. Wang Yubo. China Agricultural Resources and Regionalization. 2019(03)

[10] Analysis of the Reasons and Transformation Paths of China's Land Finance [J]. Jing Tingru, Yao Yue. Financial Theory Research. 2017(06)

[11] The influence of the new extension of the new economic normal on the solvency of local governments and the countermeasures[J]. Luan Yan. Journal of Liaoning University (Philosophy and Social Sciences Edition). 2017(05)
[12] Difficulties faced by local government land finance under the new economic normal and countermeasures[J]. Tao Zeliang, Ma Xiaoyan. Modern Management Science. 2017(09)

[13] Analysis of the causes of land finance in Henan Province under the new economic normal [J]. Mark Lin. Journal of Luoyang Normal University. 2017(05) 